\title{
Masonry Compressive Strength Prediction Using Artificial Neural Networks
}

\author{
Panagiotis G. Asteris ${ }^{1(\bowtie)}$, Ioannis Argyropoulos ${ }^{1}$, Liborio Cavaleri ${ }^{2}$, \\ Hugo Rodrigues ${ }^{3}$, Humberto Varum ${ }^{4}$, Job Thomas ${ }^{5}$, \\ and Paulo B. Lourenço ${ }^{6}$ \\ ${ }^{1}$ Computational Mechanics Laboratory, School of Pedagogical \\ and Technological Education, Heraklion, Athens, Greece \\ panagiotisasteris@gmail.com \\ 2 Department of Civil, Environmental, \\ Aerospace and Materials Engineering (DICAM), \\ University of Palermo, Palermo, Italy \\ 3 RISCO, Department of Civil Engineering, \\ Polytechnic Institute of Leiria, Leiria, Portugal \\ ${ }^{4}$ Civil Engineering Department, \\ Faculty of Engineering of the University of Porto, Porto, Portugal \\ 5 Department of Civil Engineering, \\ Cochin University of Science and Technology, Cochin, Kerala, India \\ ${ }^{6}$ Department of Civil Engineering, ISISE, \\ University of Minho, Guimarães, Portugal
}

\begin{abstract}
The masonry is not only included among the oldest building materials, but it is also the most widely used material due to its simple construction and low cost compared to the other modern building materials. Nevertheless, there is not yet a robust quantitative method, available in the literature, which can reliably predict its strength, based on the geometrical and mechanical characteristics of its components. This limitation is due to the highly nonlinear relation between the compressive strength of masonry and the geometrical and mechanical properties of the components of the masonry. In this paper, the application of artificial neural networks for predicting the compressive strength of masonry has been investigated. Specifically, back-propagation neural network models have been used for predicting the compressive strength of masonry prism based on experimental data available in the literature. The comparison of the derived results with the experimental findings demonstrates the ability of artificial neural networks to approximate the compressive strength of masonry walls in a reliable and robust manner.
\end{abstract}

Keywords: Artificial Neural Networks (ANNs) ·

Back-Propagation Neural Networks (BPNNs) - Building materials •

Compressive strength $\cdot$ Masonry $\cdot$ Masonry unit $\cdot$ Mortar ·

Soft-computing techniques 


\section{Introduction}

Masonry, as it is constructed with the use of natural materials, is one of the oldest building systems known to Humanity and is believed to have been in use for over 6,000 years. Also, masonry is the most widely used construction type, not only in the poverty-stricken countries, due to its low cost compared to the other modern materials, but also in developed countries, due to the aesthetic value that it provides when used in modern constructions. Furthermore, masonry structures exhibit a very good seismic behavior for usual low-rise houses, as well as, excellent thermal properties, as it can keep the structure cool in the summer and warm in the winter [1]. The fact that the masonry material is the oldest building material explains that the majority of monuments are masonry structures, meaning stone (or/and brick) elements joined together through the use of mortars.

In the light of the above, it can be clearly seen why masonry structures are so popular among the civil engineering community. Masonry structures, as an important part of our cultural and historical identity, have attracted the interest of many researchers since the early part of $20^{\text {th }}$ century. A dominant position among the first researchers involved in masonry structures is Engesser, who, in 1907, proposed in his work entitled Überweitgespanntewölbbrücken, the first formulae for the estimation of masonry compressive strength considering the mortar and unit strengths [2].

Despite the plethora of research work in the last three decades, the mechanics of masonry structures remains an open issue and, at the same time, a challenge for the practicing civil engineer. This is mainly related to the complicated, inhomogeneous and anisotropic nature of this particular structure type [3-9]. Furthermore, there not yet exists a robust quantitative method, available in the literature, which can reliably predict its strength, based on its components and its geometric and mechanical characteristics.

Masonry is composed of different materials, namely: the masonry units and the mortar phase. Masonry units may be either solid or hollow and may be made of a wide variety of materials. Clay bricks, blocks of stone, concrete blocks, pressed earth bricks, calcium silicate bricks, soft mud bricks etc. are some examples of masonry units used in masonry construction. The two material phases in masonry are joined by a weak interface and hence masonry is generally weak in tension. Masonry structures are therefore expected to resist only compressive forces [10]. The conventional design practice emphasizes that masonry structures are subjected to compressive stresses alone $[11,12]$ and hence an accurate determination of compressive strength is extremely important. Empirical values for the masonry strength are suggested in SP: 20 [13] for the design of masonry based on the unit strength and properties of mortar. Alternatively, masonry specimens can be tested to obtain a more accurate value of their compressive strength. The results of proposed equations available in the literature have a large dispersion, as will be shown in the next section. The mechanical properties of masonry structures exhibit a strong nonlinear nature derived from the parameters involved in their structure; it is this nonlinear behaviour that makes the development of an analytical formula for the prediction of the mechanical properties using deterministic methods a rather difficult task. 
Based on the above non-linear nature of the parameters involved in the mechanical behavior of masonry, as well as on the limitations of deterministic methods to give a reliable and robust prediction regarding the compressive strength, the last three decades, soft-computing techniques, such as artificial neural networks (ANNs), have come to contribute to the solution of the problem.

ANNs have emerged over the last decades as an attractive meta-modelling technique applicable to a vast number of scientific fields, including material science. An important characteristic of ANNs is that they can be used to build soft-sensors, i.e., models with the ability to estimate critical quantities without having to measure them [14]. In particular, such surrogate models can be constructed after a training process with only a few available data, which can be used to predict pre-selected model parameters, reducing the need for time- and money-consuming experiments.

To the authors' knowledge, there is no many attempts to apply Neural Network (NN) for the prediction of masonry behavior in general. NNs have been used in many ways for various other problems in the literature. Thus far, the literature includes studies in which ANNs were used for predicting the mechanical properties of concrete materials [15-23]. In the study of Asteris et al. [23] ANNs were used to estimate the compressive strength of self-compacting concrete through a training process, involving eleven input parameters and one output parameter, which is compressive strength of concrete. Moreover, similar methods such as fuzzy logic and genetic algorithms have also been used for modelling the compressive strength of concrete [24-32]. A detailed state-of-the-art report can be found in earlier literatures [33-38].

In this context, in the work presented herein, the modelling of the mechanical characteristics of masonry structures materials has been investigated in-depth using soft-computing techniques such as surrogate models. In particular, this study investigates the application of Artificial Neural Networks (ANNs) models for the prediction of the compressive strength of masonry prisms. Specifically, for the development and the training of NN models, a database consisting of 232 specimens, taken from the literature, was utilized. The compressive strength of masonry unit, the compressive strength of mortar, the height-to-thickness ratio of masonry prism, the volume fraction of masonry unit and the volume ratio of bed joint were used as input parameters, while the value of compressive strength was used as output parameter. The optimum NN model developed in this study has proven to be very successful, exhibiting very reliable predictions.

\section{Literature Review}

For the determination of the masonry wall compressive strength $\left(f_{w c}\right)$, several semiempirical expressions are available in the literature [2, 10, 39-53]. Common feature of these expressions, global effects contributing to the system resistance, such as buckling-effects or local-compression resistance are not considered.

The majority of these proposals [2, 10, 39-42, 46-53], in the form of the first formula proposed by Engesser in 1907 [2], take under consideration only the compressive strengths of brick and mortar, while only a few proposals pay attention to the height-to-thickness ratio of masonry prism (Fig. 1), and only two proposals [12, 43] 
take into account the volume fraction of masonry unit and the volume ratio of bed joint mortar which are used as input parameters. In Table 1, the most representative formulae (from the literature) are being presented, concerning the estimation of masonry prism compressive strength.
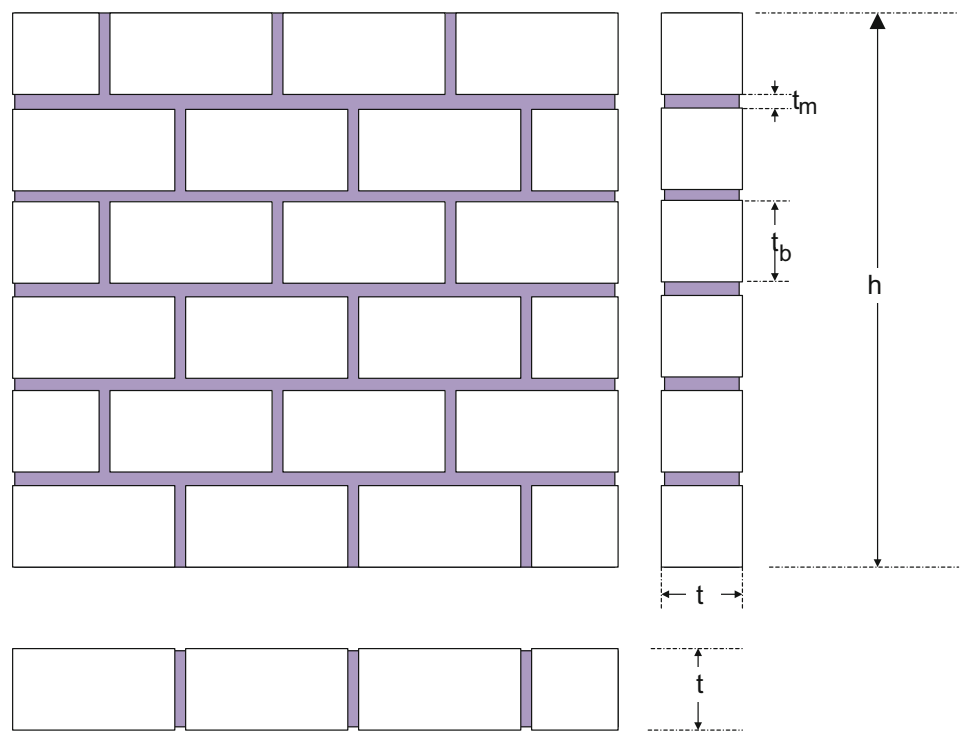

Fig. 1. Geometry of masonry wall prism.

Recently, Thaickavil and Thomas [12] have been proposed a formula that takes into account the majority of the parameters that affect the masonry compressive strength. The authors [12] carried out regression analysis on a plethora of test data (232 datasets) corresponding to the masonry unit strength of 3.1 to $127.0 \mathrm{MPa}$, mortar strength of 0.3 to $52.6 \mathrm{MPa}$ and $\mathrm{h} / \mathrm{t}$ ratio of 1.15 to 5.75 , have proposed the following formula:

$$
f_{w c}=\frac{0.54 \times f_{b c}^{1.06} \times f_{m c}^{0.004} \times V F_{b}^{3.3} \times V R_{m H}^{0.6}}{(h / t)^{0.28}}
$$

where $V F_{b}$ is the volume fraction of brick, while $V R_{m H}$ is the volume ratio of bed joint to mortar and are defined by the following equations:

$$
V F_{b}=\frac{V_{u}}{V_{p}}
$$


where $V_{u}$ is the volume of masonry units and $V_{p}$ is the volume of prism.

$$
V R_{m H}=\frac{V_{m H}}{V_{m H}+V_{m V}}
$$

where $V_{m H}$ is the volume fraction of mortar in horizontal joints and $V_{m V}$ is the volume fraction of mortar in vertical joints. More specifically, the volume fraction is obtained by dividing the respective volume with the corresponding total volume in the prism. The above proposed analytical formula (Eq. 3) seems to be the most reliable for the determination of masonry compressive strength among a plethora of proposed equations available in the literature [2, 10, 39-53].

Table 1. Formulae for the estimation of masonry compressive strength.

\begin{tabular}{r|l|l|l}
\hline No. & Reference & & Formula \\
\hline 1 & Engesser & {$[2]$} & $f_{w c}=\frac{1}{3} f_{b c}+\frac{2}{3} f_{m c}$ \\
\hline 2 & Bröcker & {$[39]$} & $f_{w c}=0.68 f_{b c}^{1 / 2} f_{m c}^{1 / 3}$ \\
\hline 3 & Mann & {$[40]$} & $f_{w c}=0.83 f_{b c}^{0.66} f_{m c}^{0.18}$ \\
\hline 4 & Henry and Malek & {$[41]$} & $f_{w c}=0.317 f_{b c}^{0.531} f_{m c}^{0.208}$ \\
\hline 5 & Dayaratnam & {$[42]$} & $f_{w c}=0.275 f_{b c}^{0.5} f_{m c}^{0.5}$ \\
\hline 6 & Rozza & {$[43]$} & $f_{w c}=\left(v_{u} f_{b c}+0.8 v_{m} f_{m c}\right) / 10$ \\
\hline 7 & Bennett et al. & {$[44]$} & $f_{w c}=0.3 f_{b c}$ \\
\hline 8 & AS 3700 & {$[45]$} & $f_{w c}=\mathrm{K}_{h} \mathrm{~K}_{m} f_{b c}^{0.5}$ \\
\hline 9 & Dymiotis and Gutlederer & {$[46]$} & $f_{w c}=0.3266 f_{b c} \times\left(1-0.0027 f_{b c}+0.0147 f_{m c}\right)$ \\
\hline 10 & Eurocode 6 & {$[47]$} & $f_{w c}=\mathrm{K} f_{b c}^{0.7} f_{m c}^{0.3}$ \\
\hline 11 & Kaushik et al. & {$[10]$} & $f_{w c}=0.317 f_{b c}^{0.866} f_{m c}^{0.134}$ \\
\hline 12 & Gumaste et al. & {$[48]$} & $f_{w c}=0.63 f_{b c}^{0.49} f_{m c}^{0.32}$ \\
\hline 13 & Christy et al. & {$[49]$} & $f_{w c}=0.35 f_{b c}^{0.65} f_{m c}^{0.25}$ \\
\hline 14 & Garzón-Roca et al. & {$[50]$} & $f_{w c}=0.53 f_{b c}+0.93 f_{m c}-10.32$ \\
\hline 15 & Sarhat and Sherwood & {$[51]$} & $f_{w c}=0.886 f_{b c}^{0.75} f_{m c}^{0.18}$ \\
\hline 16 & Lumantarna et al. & {$[52]$} & $f_{w c}=0.75 f_{b c}^{0.75} f_{m c}^{0.31}$ \\
\hline 17 & Kumavat & {$[53]$} & $f_{w c}=0.69 f_{b c}^{0.6} f_{m c}^{0.35}$ \\
\hline
\end{tabular}

$f_{w c}$ is the masonry compressive strength; $f_{b c}$ is the brick compressive strength;

$f_{m c}$ is the mortar compressive strength; $v_{u}$ is the relative volume of unit; $v_{m}$ is the relative volume of mortar;

$\mathrm{K}$ is a constant in Eurocode 6 formula, modified according to the National Annex for different countries. The value of this constants in the UK is 0.52 [54] while in Greece 0.20 to 1.00 depending on brick/block unit properties and their arrangement;

$\mathrm{K}_{h}$ is a factor in Australian AS 3700 [45]code that accounts for the ratio of unit height to mortar joint thickness (1.3 for blocks of $190 \mathrm{~mm}$ high blocks and mortar joints with $10 \mathrm{~mm}$ thickness);

$\mathrm{K}_{m}$ is also a factor in Australian AS 3700 [45] code that accounts for bedding type (1.4 for full bedding and 1.6 for face-shell bedding). 


\section{Artificial Neural Networks}

This section summarizes the mathematical and computational aspects of artificial neural networks. In general, ANNs are information-processing models configured for a specific application through a training process. A trained ANN maps a given input onto a specific output. The main advantage of a trained ANN over conventional numerical analysis procedures (e.g., regression analysis) is that the results can be produced with much less computational effort [23, 55-62].

\subsection{General}

The concept of an artificial neural network is based on the concept of the biological neural network of the human brain. The basic building block of the ANN is the artificial neuron, which is a mathematical model trying to mimic the behaviour of the biological neuron. Information is passed into the artificial neuron as input and processed with a mathematical function leading to an output that determines the behaviour of the neuron (similar to fire-or-not situation for the biological neuron). Before the information enters the neuron, it is weighted in order to approximate the random nature of the biological neuron. A group of such neurons consists of an ANN in a manner similar to biological neural networks. In order to set up an ANN, one needs to define: (i) the architecture of the ANN; (ii) the training algorithm, which will be used for the ANN learning phase; and (iii) the mathematical functions describing the mathematical model. The architecture or topology of the ANN describes the way the artificial neurons are organized in the group and how information flows within the network. For example, if the neurons are organized in more than one layers, then the network is called a multilayer ANN. Regarding the training phase of the ANN, it can be considered as a function minimization problem, in which the optimum value of weights need to be determined by minimizing an error function. Depending on the optimization algorithms used for this purpose, different types of ANNs exist. Finally, the two mathematical functions that define the behaviour of each neuron are the summation function and the activation function. In the present study, back-propagation neural network (BPNN) is used, which is described in the next section.

\subsection{Architecture of BPNN}

A BPNN is a feed-forward, multilayer network [55], i.e., information flows only from the input towards the output with no feedback loops, and the neurons of the same layer are not connected to each other, but they are connected with all the neurons of the previous and subsequent layer. A BPNN has a standard structure that can be written as

$$
\mathrm{N}-\mathrm{H}_{1}-\mathrm{H}_{2}-\cdots-\mathrm{H}_{\mathrm{NHL}}-\mathrm{M}
$$

where $\mathrm{N}$ is the number of input neurons (input parameters); $\mathrm{H}_{\mathrm{i}}$ is the number of neurons in the $\mathrm{i}$-th hidden layer for $\mathrm{i}=1, \ldots$, NHL; NHL is the number of hidden layers; and $\mathrm{M}$ is the number of output neurons (output parameters). Figure 2 depicts an example of a BPNN composed of an input layer with 5 neurons, two hidden layers with 8 and 3 neurons respectively, and an output layer with 2 neurons, i.e., a 5-8-3-2 BPNN. 
A notation for a single node (with the corresponding R-element input vector) of a hidden layer is presented in Fig. 3.

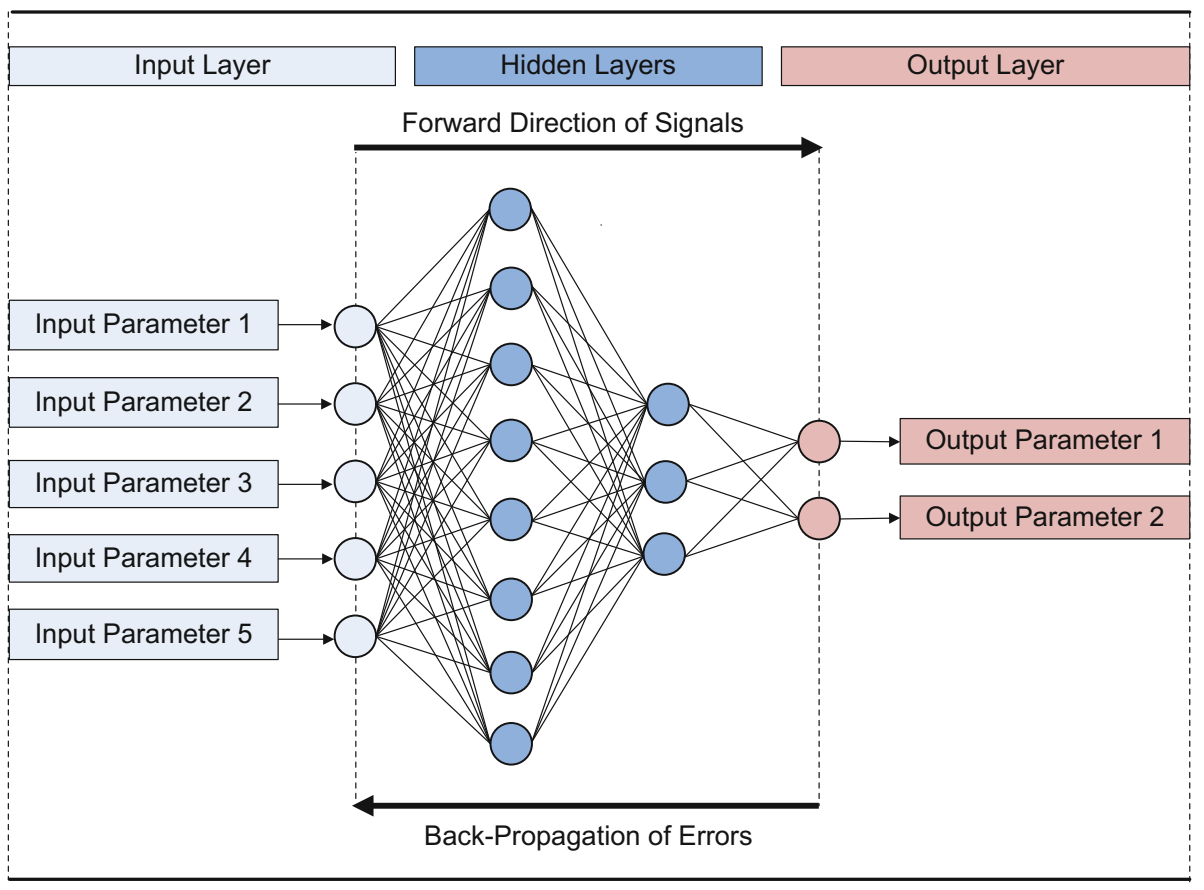

Fig. 2. Architecture of a 5-8-3-2 BPNN model.

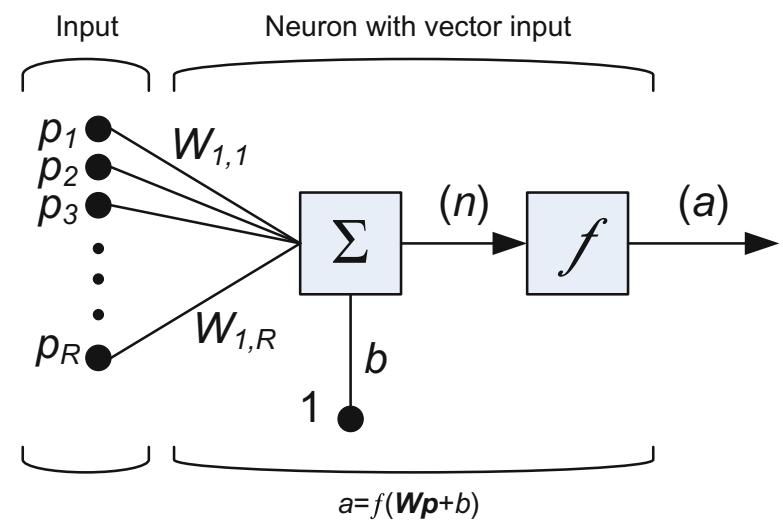

Fig. 3. A neuron with a single R-element input vector. 
For each neuron $i$, the individual element inputs $\mathrm{p}_{1}, \ldots, \mathrm{p}_{\mathrm{R}}$ are multiplied by the corresponding weights $w_{i, 1}, \ldots, w_{i, R}$ and the weighted values are fed to the junction of the summation function, in which the dot product $(\mathrm{W} \cdot \mathrm{p})$ of the weight vector $\mathrm{W}=\left[\mathrm{w}_{\mathrm{i}, 1}, \ldots, \mathrm{w}_{\mathrm{i}, \mathrm{R}}\right]$ and the input vector $\mathrm{p}=\left[\mathrm{p}_{1}, \ldots, \mathrm{p}_{\mathrm{R}}\right]^{\mathrm{T}}$ is generated. The threshold $\mathrm{b}$ (bias) is added to the dot-product forming the net input $\mathrm{n}$, which is the argument of the transfer function $f$ :

$$
n=W \cdot p=w_{i, 1} p_{1}+w_{i, 2} p_{2}+\ldots+w_{i, R} p_{R}+b
$$

The choice of the transfer (or activation) function $f$ may strongly influence the complexity and performance of the ANN. Although different type of functions are available, sigmoidal transfer functions are the most commonly used. In the present study, the Logistic Sigmoid and the Hyperbolic Tangent transfer functions were found to be appropriate for the problem investigated. During the training phase, the training data are fed into the network which tries to create a mapping between the input and the output values. This mapping is achieved by adjusting the weights in order to minimise the following error function:

$$
E=\sum\left(x_{i}-y_{i}\right)^{2}
$$

where $x_{i}$ and $y_{i}$ are the measured value and the prediction of the network, respectively, within an optimization framework. The training algorithm used for the optimization plays a crucial role in building a quality mapping, thus an exhaustive investigation was performed in order to find the most suitable for this problem. The most common method used in the literature is the back-propagation technique, in which, as stated by its name, the information propagates to the network in a backward manner in order to adjust the weights and minimize the error function. To adjust the weights properly, a general method called gradient descent is applied, in which the gradients of the error function with respect to the network weights is calculated. Further discussion on the training algorithms is given in the numerical example section.

\section{Results and Discussion}

This section presents the process for tuning optimum ANNs used for the prediction of the compressive strength of masonry walls, based on experimental data available in the literature.

\subsection{Experimental - Database}

A prerequisite for the successful function of artificial neural networks is the use of an extended and reliable database, capable of training the system. In the case of masonry walls this presents several difficulties due to several factors.

First of all, it is obvious that the production of a very large number of specimens can be a rather difficult, exorbitant and time-consuming procedure. Apart from that, state of the art facilities and laboratories are needed in order for the properties of the 
samples to be as homogenous as possible, while the time between the production of the specimen and its actual measurement, the samples must be properly stored and cured, a process that demands plenty of space with specific requirements. It has also been observed that homogeneity of samples that were created inside a specific laboratory with the same staff and under the same conditions cannot be always maintained, resulting in variations in their properties. Namely, for the case of compressive strength of masonry walls, deviations greater than $\pm 20 \%$ has been observed in the literature [63]. For all these reasons, researchers face a major difficulty obtaining an adequate amount of experimental data capable of training the ANNs, yet this issue can be addressed by using additional data from other published databases.

In addition, the mortars and masonry units are composite materials, consisting of a binder material and aggregates, while in most cases additives are used, either natural or manufactured or both. Thus, mortars are produced through the mix of water with different natural/manufactured raw materials. During the data collection process, it is important to distinguish the necessary mix parameters, while it is of crucial importance to be accurate regarding the type of raw materials used, in order to train the system appropriately. For example, the use of Ordinary Portland cement (OPC) in the mortar mix will have a different effect on the final compressive strength values when compared to the use of white cement or high alumina cement; thus, if different types of cement were used in the mortars of masonry specimens included in the database, it must be appropriately described to the ANN in order to account for its influence.

Similarly, the bricks that formulate the masonry units may have a wide range of properties that is based on their production procedures along with the materials used. Hollow or solid bricks can be found as masonry units in various researches, that might have been manufactured using common burnt clay, sand lime, concrete, fly ash clay etc. having vastly varying properties. Hence, their compressive strength or deformation characteristics when subjected to external load or compressive stresses will be varying accordingly.

To recapitulate, it is common for adequate experimental databases to be compiled through the accumulation of smaller databases acquired by different researchers and available relevant literature. During the process of compiling the database, the reliability of each individual database has to be examined, while the raw materials that were used must be adequately described (dimensions and properties of each material along with the geometry of the masonry units). Furthermore, it is important that the same standards have been followed during the experimental procedure, in order for the results to be comparable and the comparison to be meaningful. An adequate number of specimens must have tested in order for the values to be statistically acceptable; a small amount of tested specimens, regardless of credibility, cannot give a result that can be considered reliable. When training an $\mathrm{ANN}$, in addition to the reliability of the database, it is crucial that the values of the input parameters (mortar mix synthesis parameters and specimen age) cover all possible value ranges of the parameters.

It is no exaggeration to state that the reliability of the optimum developed neural network is crucially dependent on the reliability of the experimental data, thus confirming the famous expression in the field of informatics Garbage In, Garbage Out (GIGO). Predictive analytics begins with good data; more data doesn't necessarily mean better data. A successful predictive analytics project requires, first and fore-most, relevant and accurate data. 
In the light of the above a vast database has been composed that consists of 232 experimental data sets (Table 2) that have been obtained from 21 different experimental published works $[10,12,48,52,64-80]$. During the experimental data selection from the literature it was taken under consideration the compressive strength of the masonry brick $\left(f_{b}\right)$, the compressive strength of mortar $\left(f_{m}\right)$, the height-to-thickness ratio of the masonry prism $(h / t)$, the volume fraction of the masonry brick $\left(V F_{b}\right)$ and the volume ratio of bed joint mortar $\left(V R_{m H}\right)$.

Thaickavil and Thomas [12] published 64 data sets, in which 32 of them were made out of cement stabilized pressed earth units and 32 out of them using burnt clay units, with an average compressive strength of 4.56 and $6.68 \mathrm{MPa}$ respectively. In each category, 8 different configurations were formed implementing 4 different mortar proportions (M1 (1:6), M2 (1:5), M3 (1:4) and M4 (1:3)) in each configuration that were prepared using Ordinary Portland cement (OPC) and river sand conforming to Zone II of IS: 383 [81]. The compressive strength of the mortars varied between 13.60 and $35.50 \mathrm{MPa}$, while they were determined through testing cubes of $50 \mathrm{~cm}^{2}$ face area as per IS: 2250 [82]. Based on the 64 produced configurations, 192 brick masonry prisms were created in total (3 masonry units per configuration). The dimensions of half of the masonry units were $190 \times 113 \times 100 \mathrm{~mm}^{3}$ (from cement stabilized pressed earth bricks) while the dimensions of the rest were $210 \times 96 \times 50 \mathrm{~mm}^{3}$ (from burnt clay bricks). These brick masonry units were later capped with a 1-2 $\mathrm{mm}$ thin layer of dental plaster in order to level the contact surface between the specimen face and platens of the testing machine. The results from the performed analyses enabled the researchers to draw useful conclusions concerning the effect of (a) the strength of the brick, (b) the strength of the mortar, (c) the height-to-thickness ratio of the prism, (d) the volume fraction of brick and (e) the volume ratio of bed joint to mortar, on the compressive strength of the masonry prisms $\left(f_{w c}\right)$.

In the research work of Francis et al. [80], the effect of joint (mortar) thickness on the compressive strength of brickwork was investigated. 33 data sets of four-high stackbonded prisms were created, in which the thickness of the mortar varied, while using 2 types of bricks (solid and perforated) with the mean dimensions taken from a significantly large sample of individual measurements. The properties of the mortar derived from a 1:1:6 mix (Portland cement: lime: sand) with its compressive strength varied between 0.30 and 52.60 MPa. Following the same pattern, the compressive strength of the bricks presented a wide dispersion since the recorded values were spread between 3.10 and $127.00 \mathrm{MPa}$ after being measured from 12 single bricks. In each type of brick, six prisms were created with mortar joints of approximately $10.00 \mathrm{~mm}$ and $15.00 \mathrm{~mm}$ thickness and four prisms of each brick type with $25.00 \mathrm{~mm}$ mortar, while four more prisms in each brick type were created with as thin joints as possible. In each case a layer of mortar was placed at the top and bottom of each prism and then the prisms were cured for 14 days in air inside the laboratory. It was observed that thinner joints make the brick units stronger. Hence, it was concluded that the bond strength is of paramount importance when bending or eccentricity of load produces tensile stresses.

Vermeltfoort [78] stated that strength and stiffness of both brick and mortar is a crucial factor influencing the compressive strength of masonry units. Through the implementation of 29 data sets, 170 masonry specimens were finally created and tested. A large variation in the test configuration was achieved by altering the mechanical 
Table 2. Data from experiments published in literature.

\begin{tabular}{|c|c|c|c|c|c|}
\hline \multirow{2}{*}{$\begin{array}{c}\text { No. } \\
1\end{array}$} & \multicolumn{2}{|l|}{ Reference } & \multirow{2}{*}{$\begin{array}{l}\text { Type of unit } \\
\text { PEB \& BCLB }\end{array}$} & \multirow{2}{*}{$\begin{array}{l}\begin{array}{l}\text { Number of } \\
\text { datasets }\end{array} \\
64\end{array}$} & \multirow{2}{*}{$\begin{array}{l}\text { Compressive strength } \\
\text { [MPa] } \\
0.70-3.20\end{array}$} \\
\hline & $\begin{array}{l}\text { Thaickavil and } \\
\text { Thomas }\end{array}$ & {$[12]$} & & & \\
\hline 2 & $\begin{array}{l}\text { Ravula and } \\
\text { Subramaniam }\end{array}$ & {$[64]$} & SFCLB & 2 & $5.80-8.00$ \\
\hline 3 & Singh and Munjal & [65] & $\mathrm{BCB}$ & 12 & $2.10-11.60$ \\
\hline 4 & Zhou et al. & [66] & $\mathrm{HCB}$ & 12 & $10.20-27.00$ \\
\hline 5 & $\begin{array}{l}\text { Balasubramanian } \\
\text { et al. }\end{array}$ & [67] & CLB & 1 & $2.80-2.80$ \\
\hline 6 & Vindhyashree et al. & {$[68]$} & SCB & 3 & $4.00-4.80$ \\
\hline 7 & Lumantarna et al. & {$[52]$} & SLCB & 14 & $6.51-30.79$ \\
\hline 8 & Nagarajan et al. & [69] & BCLB & 3 & $1.90-2.40$ \\
\hline 9 & Thamboo & [70] & HCB & 4 & $6.90-10.10$ \\
\hline 10 & $\begin{array}{l}\text { Vimala and } \\
\text { Kumarasamy }\end{array}$ & [71] & STMB & 6 & $0.70-1.60$ \\
\hline 11 & Reddy et al. & [72] & PEB & 4 & $3.20-3.90$ \\
\hline 12 & Kaushik et al. & {$[10]$} & CLB & 12 & $2.90-8.50$ \\
\hline 13 & Gumaste et al. & [48] & TMB \& WCB & 6 & $1.30-10.00$ \\
\hline 14 & Mohamad et al. & [73] & HCB & 6 & $7.50-11.70$ \\
\hline 15 & $\begin{array}{l}\text { Brencich and } \\
\text { Gambarotta }\end{array}$ & [74] & SLCB & 2 & $3.90-13.50$ \\
\hline 16 & $\begin{array}{l}\text { Bakhteri and } \\
\text { Sambasivam }\end{array}$ & [75] & SLCB & 6 & $9.10-16.90$ \\
\hline 17 & Ip & [76] & FS \& SLCB & 4 & $11.00-41.00$ \\
\hline 18 & Hossein et al. & [77] & BCLB & 1 & $18.20-18.20$ \\
\hline 19 & Vermeltfoort & [78] & $\begin{array}{l}\text { SFCLB, PFB, WCB, } \\
\text { CLSLB }\end{array}$ & 29 & $3.90-39.80$ \\
\hline 20 & McNary and Abrams & [79] & SMP \& MCU & 8 & $19.70-48.20$ \\
\hline \multirow[t]{2}{*}{21} & Francis et al. & {$[80]$} & SLB \& PFB & 33 & $7.80-21.90$ \\
\hline & \multicolumn{3}{|l|}{ Total } & 232 & $0.70-48.20$ \\
\hline
\end{tabular}

PEB: Pressed Earth bricks

SFCLB: Soft Clay bricks

SCB: Solid Concrete bricks

CLB: Clay bricks

TMB: Table Mounted brick

FS: Flagstone

CLSLB: Calcium Silicate bricks

MCU: Modular Cored unit

BCLB: Burnt Clay brick

HCB: Hollow Concrete bricks

STMB: Stabilized Mud blocks

SLCB: Solid Clay bricks

WCB: Wire Cut bricks

PFB: Perforated bricks

SMP: Standard Modular paver

SLB: Solid bricks 
properties of bricks, using 3 soft mud brick categories (PO, VE, ER), 2 wire cut brick (JB, JG) and 1 calcium silicate (CS), with their compressive strength varying between 27.00 and $127.00 \mathrm{MPa}$. In addition, the use of mortars of different compressive strength (4.00 to $48.00 \mathrm{MPa}$ ) greatly facilitated towards the preparation of the aforementioned configurations. Finally, the preparation of 3 different geometries (wide, narrow and high) resulted into specimens with dimensions of $430 \times 100 \times 340 \mathrm{~mm}^{3}$, $200 \times 100 \times 340 \mathrm{~mm}^{3}$ and $100 \times 100 \times 500 \mathrm{~mm}^{3}(\mathrm{~L} \times \mathrm{D} \times \mathrm{H})$ respectively. The researcher concluded that the equation of the characteristic compressive strength of masonry that is found on CEN-EC6 [83] gives an approximation of the actual/measured value with a deviation of $8 \%$ for groups of more than 3 specimens.

Based on the above database, each input training vector $\mathrm{p}$ is of dimension $1 \times 5$ and consists of five parameters, namely, the compressive strength of masonry unit, the compressive strength of mortar, the height-to-thickness ratio of masonry prism, the volume fraction of masonry unit and the volume ratio of bed joint. The corresponding output training vectors are of dimension $1 \times 1$ and consist of the value of the compressive strength of the masonry prism. Their mean values together with the minimum and maximum values, as well as the standard deviation (STD) values are listed in Table 3.

Table 3. The input and output parameters used in the development of BPNNs.

\begin{tabular}{|c|c|c|c|c|c|c|}
\hline \multirow[t]{2}{*}{ Variable } & \multirow[t]{2}{*}{ Units } & \multirow[t]{2}{*}{ Type } & \multicolumn{4}{|c|}{ Data used in NN models } \\
\hline & & & Min & Average & Max & STD \\
\hline $\begin{array}{l}\text { Volume fraction of masonry } \\
\text { unit (brick) }\end{array}$ & - & Input & 0.76 & 0.89 & 0.98 & 0.04 \\
\hline $\begin{array}{l}\text { Compressive strength of } \\
\text { masonry unit (brick) }\end{array}$ & $\mathrm{MPa}$ & Input & 3.10 & 29.27 & 127.00 & 28.67 \\
\hline Compressive strength of mortar & $\mathrm{MPa}$ & Input & 0.30 & 13.85 & 52.60 & 10.79 \\
\hline $\begin{array}{l}\text { Height-to-thickness ratio of } \\
\text { masonry prism }\end{array}$ & - & Input & 1.15 & 3.27 & 5.75 & 0.99 \\
\hline $\begin{array}{l}\text { Volume ratio of bed joint } \\
\text { mortar }\end{array}$ & - & Input & 0.66 & 0.96 & 1.00 & 0.09 \\
\hline Masonry compressive strength & $\mathrm{MPa}$ & Output & 0.70 & 9.97 & 48.20 & 9.37 \\
\hline
\end{tabular}

\subsection{Training Algorithms}

For the training of the BPNN models the use of a large set of training function such as quasi-Newton, Resilient, One-step secant, Gradient descent with momentum and adaptive learning rate and Levenberg-Marquardt backpropagation algorithms has been investigated. From all these algorithms the best prediction for the non-linear behaviour of the compressive strength of masonry prism of SCC is achieved, when the Levenberg-Marquardt implemented by Levmar [84]. This algorithm appears to be the fastest method for training moderate-sized feedforward neural networks (up to several hundred weights) as well as non-linear problems. It also has an efficient implementation in MATLAB ${ }^{\circledR}$ software, because the solution of the matrix equation is a built-in function, so its attributes become even more pronounced in a MATLAB environment. 


\subsection{BPNN Model Development}

In this work, a large number of different BPNN models have been developed and implemented. Each one of these ANN models was trained over 155 data-points out of the total of 232 data-points, $(66.81 \%$ of the total number) and the validation and testing of the trained ANN were performed with the remaining 77 data-points. More specifically, 39 data-points $(16.81 \%)$ were used for the validation of the trained ANN and 38 $(16.38 \%)$ data-points were used for the testing.

The development and training of the ANNs occurs with a number of hidden layers ranging from 1 to 2 and with a number of neurons ranging from 1 to 30 for each hidden layer. Each one of the ANNs is developed and trained for a number of different activation functions, such as the Log-sigmoid transfer function (logsig), the Linear transfer function (purelin) and the Hyperbolic tangent sigmoid transfer function (tansig) [85-91].

The reliability and accuracy of the developed neural networks were evaluated using Pearson's correlation coefficient $\mathrm{R}$ and the root mean square error (RMSE). RMSE presents information on the short term efficiency which is a benchmark of the difference of predicated values about the experimental values. The lower the RMSE, the more accurate is the evaluation. The Pearson's correlation coefficient $\mathrm{R}$ measures the variance that is interpreted by the model, which is the reduction of variance when using the model. $\mathrm{R}$ values range from 0 to 1 while the model has healthy predictive ability when it is near to 1 and is not analyzing whatever when it is near to 0 . These performance metrics are good measures of the overall predictive accuracy.

Furthermore, the following new engineering index, the a20-index, is proposed for the reliability assessment of the developed ANN models:

$$
a 20-\text { index }=\frac{m 20}{M}
$$

where $M$ is the number of dataset sample and $m 20$ is the number of samples with value of rate Experimental value/Predicted value between 0.80 and 1.20 . It should be noted that for a perfect predictive model, the values of the $a 20$-index are expected to be equal to 1.00. The proposed a20-index has the advantage that its value has a physical engineering meaning which declares the amount of the samples that satisfy the predicted values with a deviation of $\pm 20 \%$, compared to experimental values.

Based on the above, a total of 3,600,000 different BPNN models have been developed and investigated in order to find the optimum NN model for the prediction of the compressive strength of masonry walls. Namely, five different cases of NN architectures that were based on the number of input parameters were investigated as it is presented in Table 4. For each case a total of 720,000 different BPNN models were developed and investigated.

The developed ANN models were sorted in a decreasing order based on the $a 20$ index value. Based on this ranking, the optimum BPNN model for the prediction of the compressive strength for each one from the five cases of NN architectures based on Input Parameters used are presented in Table 5. 
Table 4. Cases of NN architectures based on the number of input parameters that were used.

\begin{tabular}{l|l|l|l|l|l|l}
\hline \multirow{2}{*}{ Case } & \multirow{2}{*}{ Number of input parameters } & \multicolumn{5}{|c}{ Input parameters } \\
\cline { 3 - 7 } & & $\mathrm{VF}_{\mathrm{b}}$ & $\mathrm{f}_{\mathrm{b}}$ & $\mathrm{f}_{\mathrm{m}}$ & $\mathrm{h} / \mathrm{t}$ & $\mathrm{VR}_{\mathrm{mH}}$ \\
\hline I & 2 & & $\sqrt{ }$ & $\sqrt{ }$ & & \\
\hline II & 3 & & $\sqrt{ }$ & $\sqrt{ }$ & $\sqrt{ }$ & \\
\hline III & 4 & & $\sqrt{ }$ & $\sqrt{ }$ & $\sqrt{ }$ & $\sqrt{ }$ \\
\hline IV & 4 & $\sqrt{ }$ & $\sqrt{ }$ & $\sqrt{ }$ & $\sqrt{ }$ & \\
\hline V & 5 & $\sqrt{ }$ & $\sqrt{ }$ & $\sqrt{ }$ & $\sqrt{ }$ & $\sqrt{ }$ \\
\hline
\end{tabular}

Table 5. Statistical indexes of the optimum BPNN for each one from the five cases of NN architectures based on input parameters used (see also Table 4).

\begin{tabular}{|c|c|c|c|c|c|}
\hline \multirow[t]{2}{*}{ Case of input parameters } & \multirow[t]{2}{*}{ Optimum BPNN model } & \multirow[t]{2}{*}{ Data } & \multicolumn{3}{|l|}{ Indexes } \\
\hline & & & $\mathrm{R}$ & RMSE & a20-index \\
\hline \multirow[t]{4}{*}{ I } & \multirow[t]{4}{*}{$2-28-4-1$} & Training & 0.9744 & 2.0218 & 0.5677 \\
\hline & & Validation & 0.9513 & 2.8845 & 0.4872 \\
\hline & & Test & 0.9607 & 3.0847 & 0.3947 \\
\hline & & All & 0.9671 & 2.3850 & 0.5259 \\
\hline \multirow[t]{4}{*}{ II } & \multirow[t]{4}{*}{$3-8-28-1$} & Training & 0.9975 & 0.6332 & 0.9290 \\
\hline & & Validation & 0.9919 & 1.2626 & 0.7179 \\
\hline & & Test & 0.9531 & 3.2991 & 0.7368 \\
\hline & & All & 0.9867 & 1.5227 & 0.8621 \\
\hline \multirow[t]{4}{*}{ III } & \multirow[t]{4}{*}{$4-4-26-1$} & Training & 0.9961 & 0.7969 & 0.8129 \\
\hline & & Validation & 0.9763 & 1.9561 & 0.6667 \\
\hline & & Test & 0.9700 & 2.6522 & 0.5263 \\
\hline & & All & 0.9873 & 1.4899 & 0.7414 \\
\hline \multirow[t]{4}{*}{ IV } & \multirow[t]{4}{*}{$4-4-18-1$} & Training & 0.9927 & 1.0871 & 0.7290 \\
\hline & & Validation & 0.9807 & 1.7796 & 0.5385 \\
\hline & & Test & 0.9792 & 2.3673 & 0.6053 \\
\hline & & All & 0.9872 & 1.4966 & 0.6767 \\
\hline \multirow[t]{4}{*}{$\mathrm{V}$} & \multirow[t]{4}{*}{$5-7-30-1$} & Training & 0.9973 & 0.6629 & 0.9097 \\
\hline & & Validation & 0.9776 & 2.0029 & 0.6667 \\
\hline & & Test & 0.9730 & 2.8492 & 0.5263 \\
\hline & & All & 0.9869 & 1.5158 & 0.8060 \\
\hline
\end{tabular}

Based on these results, the optimum BPNN model is that of case II, which corresponds of BPNN architecture with three input parameters (Masonry unit compressive strength, mortar compressive strength and height-to-thickness ratio of masonry wall). Namely, the optimum BPNN model is that of architecture 3-8-28-1, which represents BPNN model with three input parameters, two hidden layers with 8 and 28 neurons and one output parameter (Fig. 4). As it is presented in Fig. 4, the transfer functions are Hyperbolic tangent sigmoid transfer function (tansig) for the first hidden layer, the Logsigmoid transfer function (logsig) for the second hidden layer and the Linear transfer function (purelin) for the output layer. 
All figures from Figs. 5, 6, 7 and 8, depict the comparison of the experimental values with the predicted values of the optimum BPNN model for the case of train, validation, test and all data. It is clearly depicted that the proposed optimum 3-8-28-1 BPNN predicted reliably the compressive strength of masonry prism. Also, Figs. 9 and 10 present a comparison between the exact experimental values with the predicted values of the optimum BPNN model. It is worth mentioning that for samples with experimental values of compressive strength greater than $4.00 \mathrm{MPa}$ the predicted values have a deviation less than $\pm 20 \%$ that means the value of the a20-index is 1.00 (points between the two dotted lines in Figs. 5, 6, 7 and 8).

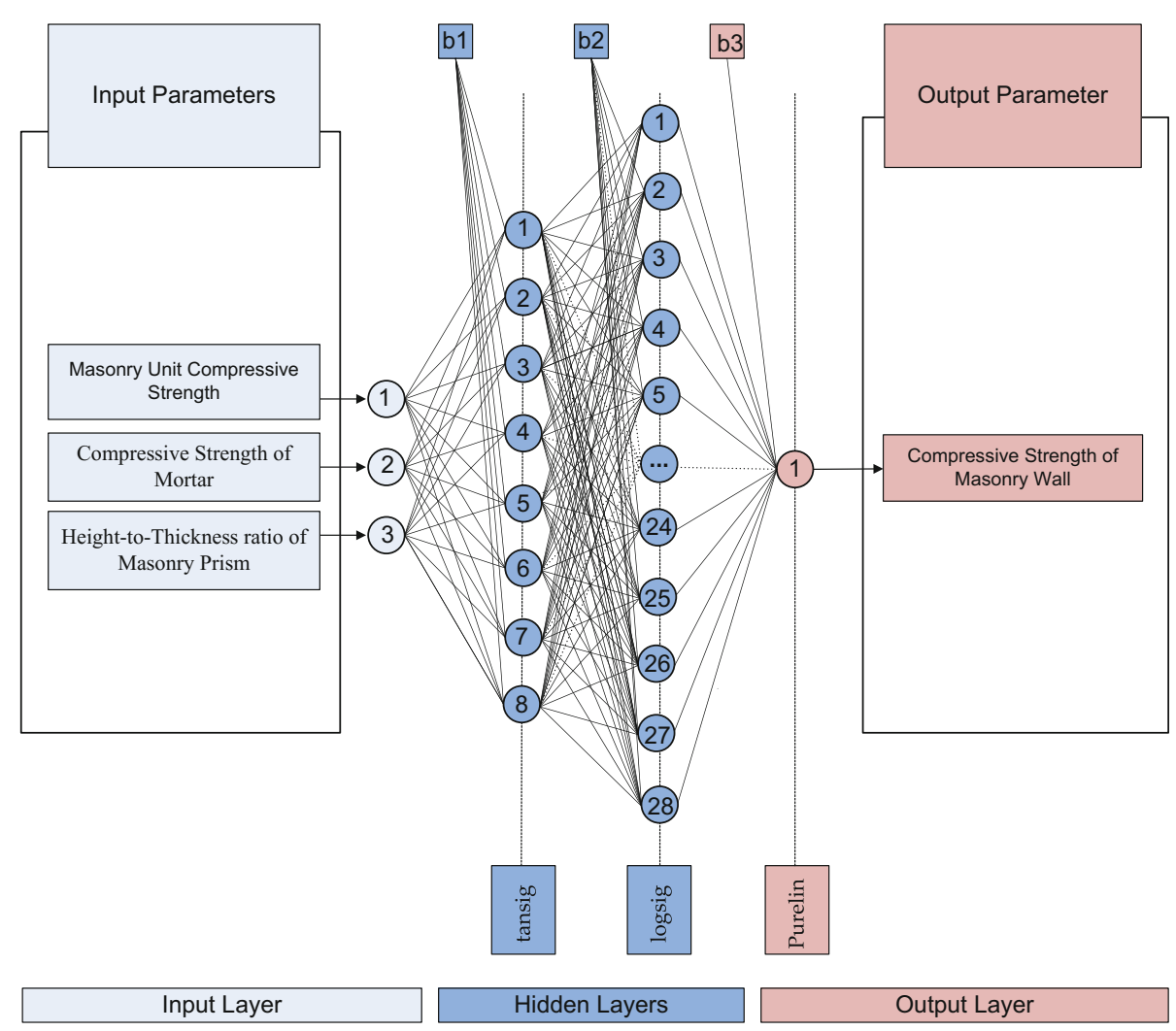

Fig. 4. Architecture of the optimum with three input parameters, two hidden layers and one output parameter 3-8-28-1 BPNN model. 


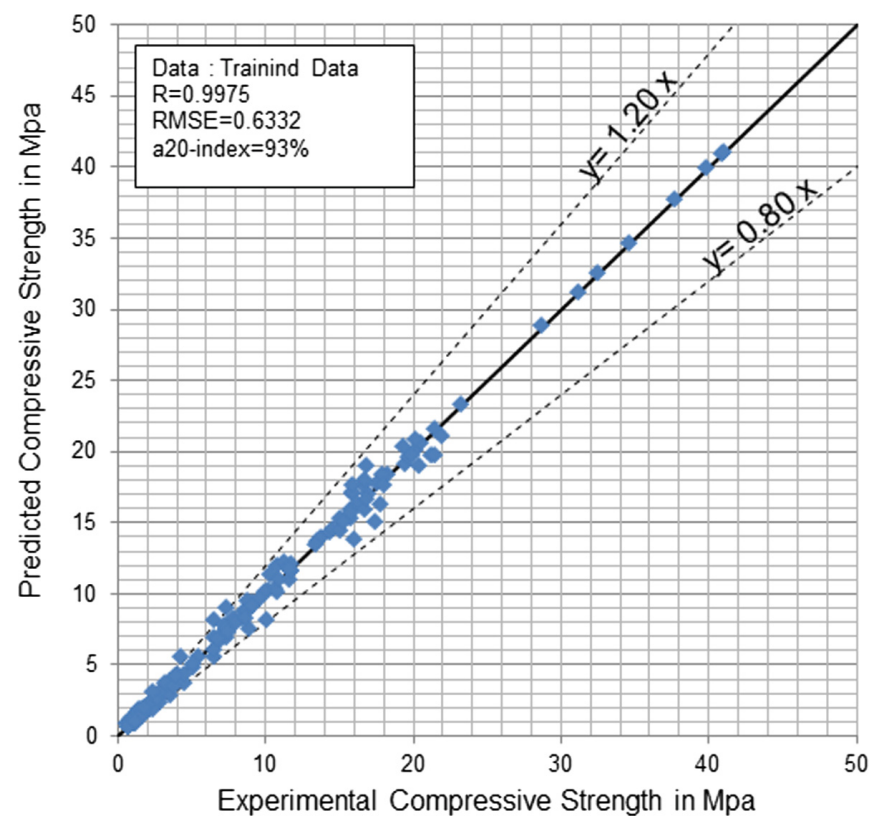

Fig. 5. Comparison of Experimental and predicted values of compressive strength for the training process.

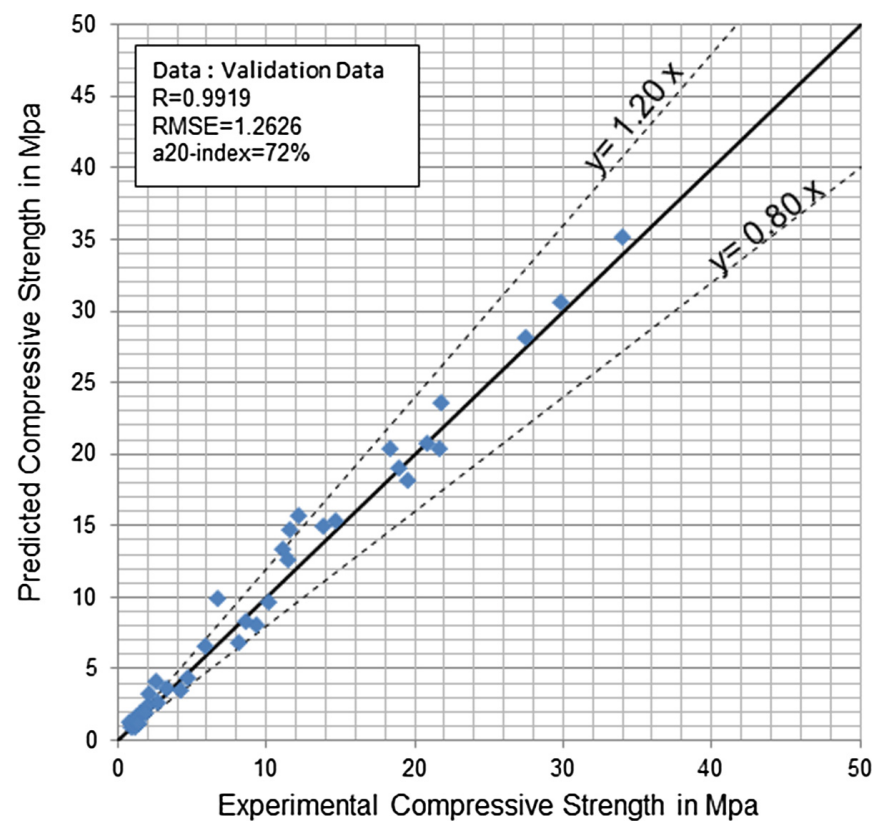

Fig. 6. Comparison of Experimental and predicted values of compressive strength for the validation process 


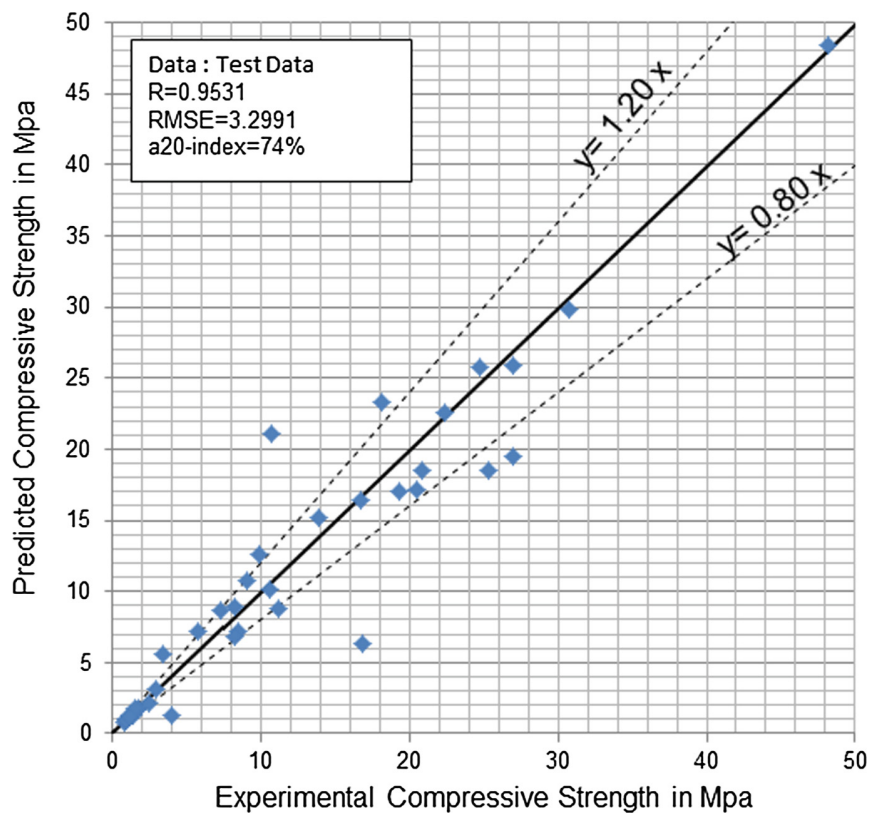

Fig. 7. Comparison of experimental and predicted values of compressive strength for the test process.

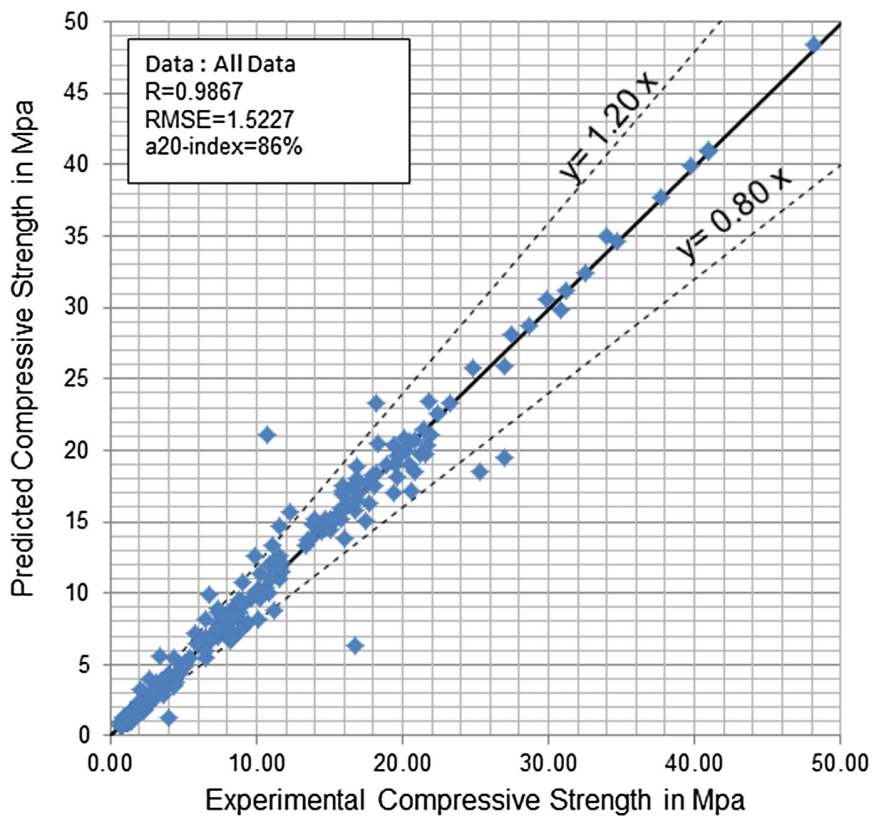

Fig. 8. Comparison of experimental and predicted values of compressive strength for all data. 


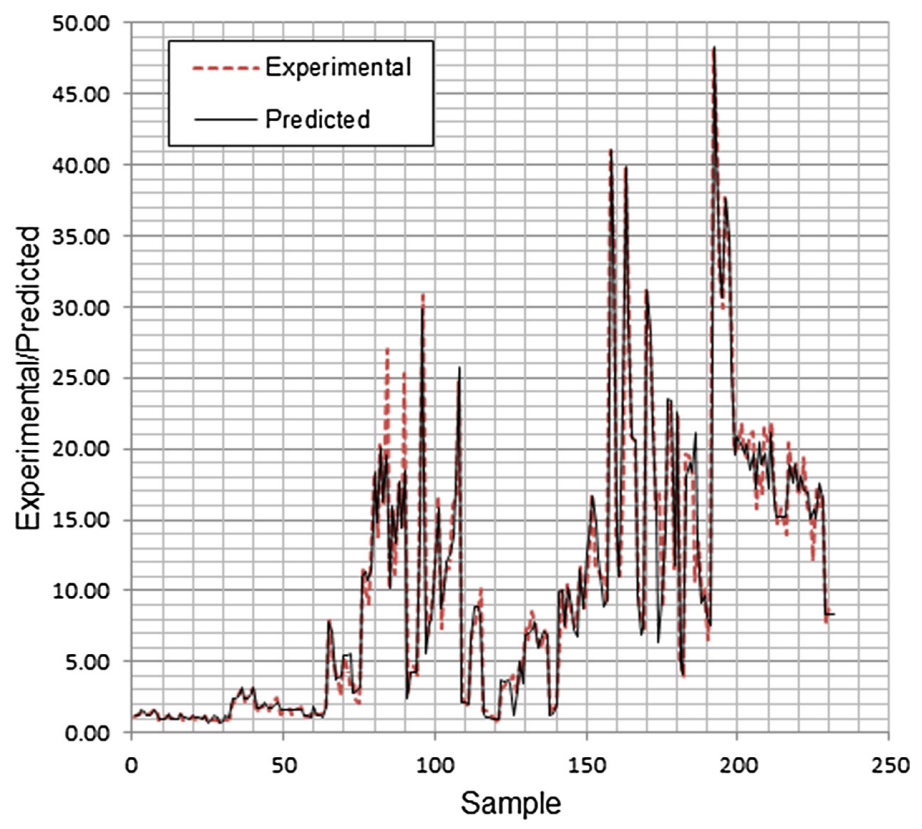

Fig. 9. Experimental vs predicted values of compressive strength for all data.

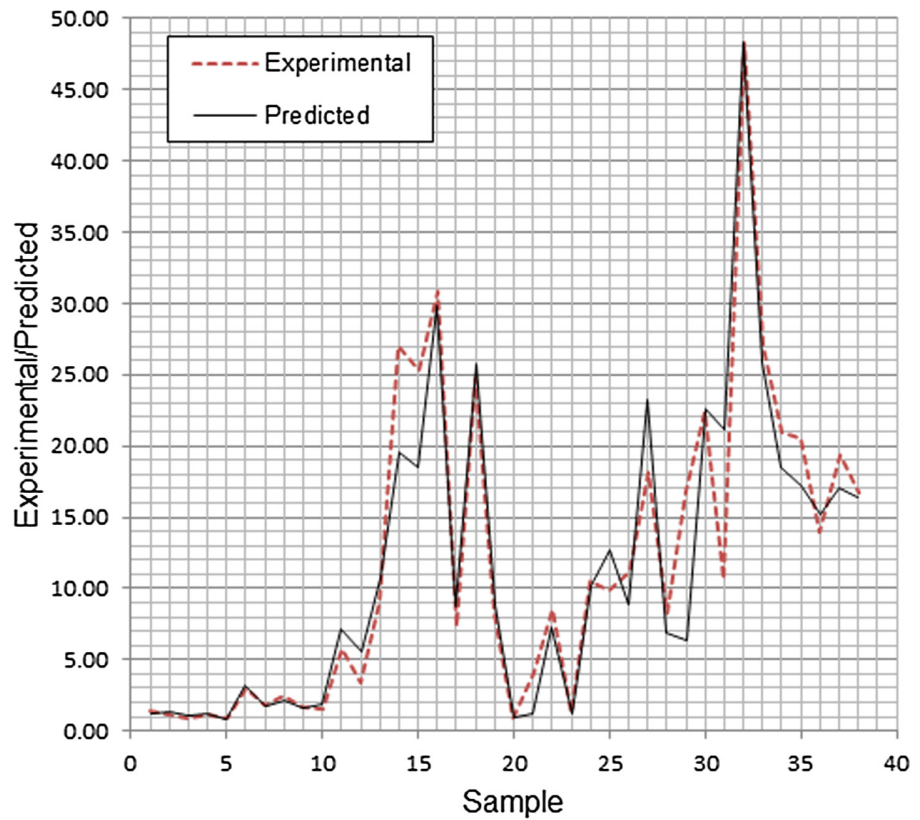

Fig. 10. Experimental vs predicted values of compressive strength for test data. 


\subsection{Comparisons with Code Provisions}

In Table 6, a comparison among the proposed BPNN model with the available in the literature models for the prediction of masonry wall compressive strength is presented, with the models being sorted based on the a20-index. It is clearly shown that the optimum BPNN model with architecture 3-8-28-1 (three input parameters, two hidden layers with 8 and 28 neurons and one output parameter the masonry prism compressive strength) predict the compressive strength of masonry wall in a reliable and robust manner. Namely, the optimum BPNN model corresponds to a value of a $a 20-1$ ndex equal to 0.8621 while for the first of the available in the literature that is the proposed formula by Thaickavil and Thomas [12] is 0.4526 .

Table 6. Ranking of the developed optimum BPNN models with the code provisions and other research formulae about the prediction of masonry prism compressive strength available in the literature based on the engineering a20-index (All Data).

\begin{tabular}{r|l|l|r|l}
\hline \multirow{2}{*}{ No. } & Model & \multicolumn{3}{l}{ Indexes } \\
\cline { 3 - 5 } & & R & RMSE & a20-index \\
\hline 1 & $3-8-28-1$ BPNN & 0.9867 & 1.5227 & 0.8621 \\
\hline 2 & $5-7-30-1$ BPNN & 0.9869 & 1.5158 & 0.8060 \\
\hline 3 & $4-4-26-1$ BPNN & 0.9873 & 1.4899 & 0.7414 \\
\hline 4 & $4-4-18-1$ BPNN & 0.9872 & 1.4966 & 0.6767 \\
\hline 5 & $2-28-4-1$ BPNN & 0.9671 & 2.3850 & 0.5259 \\
\hline 6 & Thaickavil and Thomas 2018 & 0.8660 & 4.8500 & 0.4526 \\
\hline 7 & Bennet et al. 1997 & 0.8589 & 4.9662 & 0.3621 \\
\hline 8 & Dymiotis and Gutlederer 2002 & 0.8892 & 4.4770 & 0.3491 \\
\hline 9 & Mann 1982 & 0.8943 & 4.3206 & 0.2672 \\
\hline 10 & Eurocode 6 2005 & 0.8805 & 4.4416 & 0.2629 \\
\hline 11 & Kaushik et al. 2007 & 0.8841 & 5.1618 & 0.2629 \\
\hline 12 & Kumavat et al. 2016 & 0.8652 & 4.7715 & 0.2284 \\
\hline 13 & ACI 530.99 & 0.8589 & 5.4791 & 0.2241 \\
\hline 14 & Bröcker 1963 & 0.8580 & 6.6316 & 0.1767 \\
\hline 15 & Gumaste et al. 2007 & 0.8609 & 7.4510 & 0.1724 \\
\hline 16 & Engesser 1907 & 0.7439 & 11.9769 & 0.1724 \\
\hline 17 & Sarhat et al. 2014 & 0.8913 & 8.1023 & 0.1552 \\
\hline 18 & Hendry and Malek 1986 & 0.8922 & 10.7358 & 0.1379 \\
\hline 19 & Lumantarna et al. 2014 & 0.8781 & 11.7124 & 0.1336 \\
\hline 20 & Christy et al. 2013 & 0.8887 & 7.9826 & 0.1207 \\
\hline 21 & Garzón-Roca et al. 2013 & 0.7704 & 14.6882 & 0.1034 \\
\hline 22 & Dayaratnam 1987 & 0.7880 & 9.0089 & 0.0819 \\
\hline & & & & \\
\hline
\end{tabular}




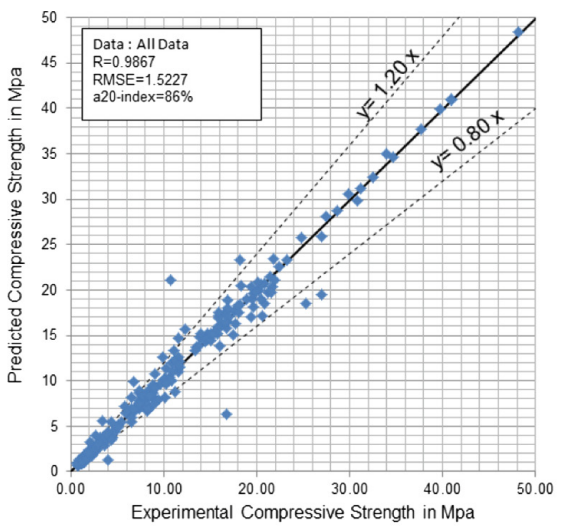

Proposed BPNN 3-8-28-1

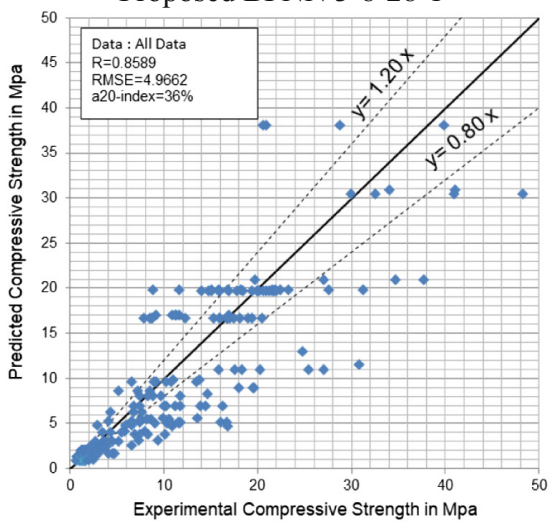

Bennet et al., 1997

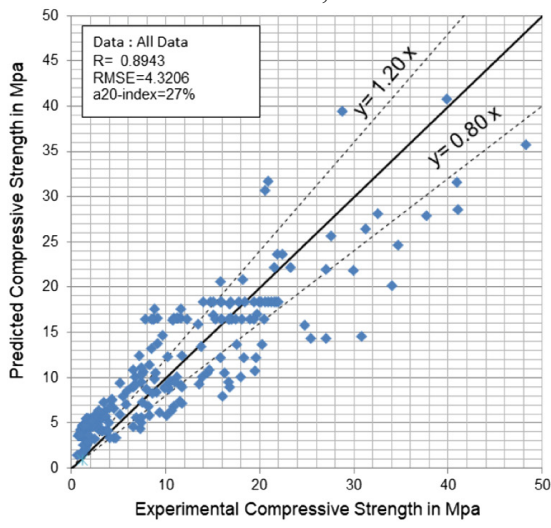

Mann, 1982

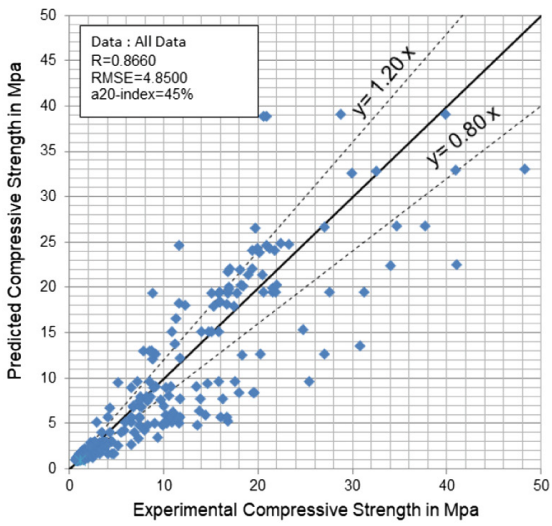

Thaickavil \& Thomas, 2018

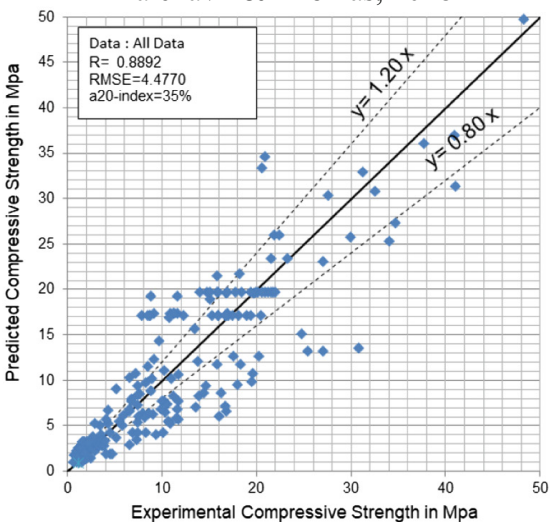

Dymiotis \& Gutlederer, 2002

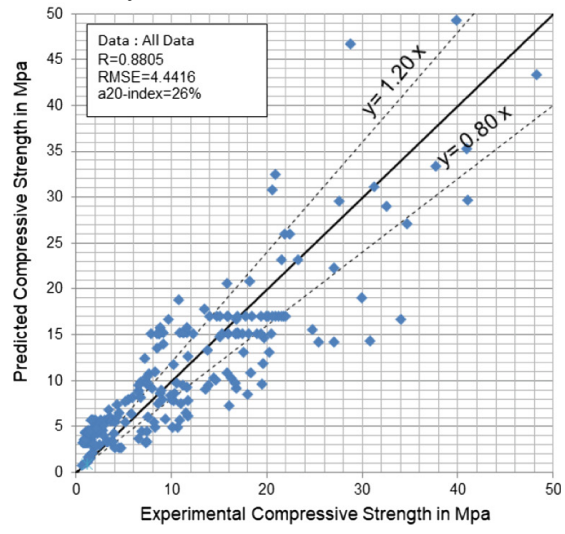

Eurocode 6, 2005

Fig. 11. Comparison of the "exact" experimental value of the compressive strength of masonry with the ones predicted by the existing empirical expressions and by the proposed BPNN model (all data). 
Furthermore, the advantages of the produced BPNN model compared to the code provisions and other research formulae are depicted in Fig. 11. The importance of graphing the data and the effect of outliers on the statistical properties of a data set should also be pointed out. For example, Anscombe [92] presented four simple data sets and even though they show identical statistical properties (mean values, standard deviation, correlation factor, etc.), they were quite different when inspected graphically. For these reasons, Fig. 11 compares the "exact" experimental value of the compressive strength of masonry with the ones predicted by the existing empirical expressions and by the proposed BPNN model.

From Fig. 11, it is also clear that the proposed 3-8-28-1 BPNN provides much more reliable values for the compressive strength of masonry prism compared to those proposed by the available equations, thus confirming the validity of the proposed NN.

\section{Conclusions}

The present study investigates the application of Artificial Neural Networks (ANNs) models for the prediction of the compressive strength of masonry walls. The comparison between the derived results and the experimental findings, clearly demonstrates the effectiveness of ANNs to build a series of soft sensors resulting in the ability to predict, in a reliable and comprehensive manner, their compressive strength.

\section{References}

1. ACI/TMS 122R-14: Guide to Thermal Properties of Concrete and Masonry Systems, Reported by ACI/TMS Committee 122, December 2014

2. Engesser, F.: Über weitgespannte wölbbrücken. Z. Architekt. Ing.-wesen 53, 403-440 (1907)

3. Syrmakezis, C.A., Asteris, P.G.: Masonry failure criterion under biaxial stress state. J. Mater. Civ. Eng. 13(1), 58-64 (2001)

4. Lourenço, P.: Computations on historic masonry structures. Prog. Struct. Mat. Eng. 4(3), 301-319 (2002)

5. Milani, G., Lourenço, P.B., Tralli, A.: Homogenised limit analysis of masonry walls, part I: failure surfaces. Comput. Struct. 84(3-4), 66-180 (2006)

6. Asteris, P.G., Antoniou, S.T., Sophianopoulos, D.S., Chrysostomou, C.Z.: Mathematical macromodeling of infilled frames: state of the art. J. Struct. Eng. 137(12), 1508-1517 (2011)

7. Chrysostomou, C.Z., Asteris, P.G.: On the in-plane properties and capacities of infilled frames. Eng. Struct. 41, 385-402 (2012)

8. Asteris, P.G., Cotsovos, D.M., Chrysostomou, C.Z., Mohebkhah, A., Al-Chaar, G.K.: Mathematical micromodeling of infilled frames: state of the art. Eng. Struct. 56, 1905-1921 (2013)

9. Asteris, P.G., et al.: Seismic vulnerability assessment of historical masonry structural systems. Eng. Struct. 62-63, 118-134 (2014)

10. Kaushik, H.B., Rai, D.C., Jain, S.K.: Stress-strain characteristics of clay brick masonry under uniaxial compression. J. Mater. Civ. Eng. 19(9), 728-739 (2007) 
11. Thomas, J.: Concrete block reinforced masonry wall panels subjected to out-of-plane monotonic lateral loading. In: Proceedings of National Conference on Recent Advances in Structural Engineering, Hyderabad, India, pp. 123-129, February 2006

12. Thaickavil, N.N., Thomas, J.: Behaviour and strength assessment of masonry prisms. Case Stud. Constr. Mater. 8, 23-38 (2018)

13. SP 20 (S\&T): Handbook on Masonry Design and Construction. Bureau of Indian Standards, New Delhi (1991)

14. Alexandridis, A.: Evolving RBF neural networks for adaptive soft-sensor design. Int. J. Neural Syst. 23, 1350029 (2013)

15. Dias, W.P.S., Pooliyadda, S.P.: Neural networks for predicting properties of concretes with admixtures. Constr. Build. Mater. 15, 371-379 (2001)

16. Lee, S.C.: Prediction of concrete strength using artificial neural networks. Eng. Struct. 25, 849-857 (2003)

17. Topçu, I.B., Saridemir, M.: Prediction of compressive strength of concrete containing fly ash using artificial neural networks and fuzzy logic. Comput. Mater. Sci. 41, 305-311 (2008)

18. Trtnik, G., Kavčič, F., Turk, G.: Prediction of concrete strength using ultrasonic pulse velocity and artificial neural networks. Ultrasonics 49, 53-60 (2009)

19. Waszczyszyn, Z., Ziemiański, L.: Neural networks in mechanics of structures and materials —new results and prospects of applications. Comput. Struct. 79, 2261-2276 (2001)

20. Douma, O.B., Boukhatem, B., Ghrici, M., Tagnit-Hamou, A.: Prediction of properties of self-compacting concrete containing fly ash using artificial neural network. Neural Comput. Appl. 28, 1-12 (2016). https://doi.org/10.1007/s00521-016-2368-7

21. Mashhadban, H., Kutanaei, S.S., Sayarinejad, M.A.: Prediction and modeling of mechanical properties in fiber reinforced self-compacting concrete using particle swarm optimization algorithm and artificial neural network. Constr. Build. Mater. 119, 277-287 (2016)

22. Açikgenç, M., Ulaş, M., Alyamaç, K.E.: Using an artificial neural network to predict mix compositions of steel fiber-reinforced concrete. Arab. J. Sci. Eng. 40, 407-419 (2015)

23. Asteris, P.G., Kolovos, K.G., Douvika, M.G., Roinos, K.: Prediction of self-compacting concrete strength using artificial neural networks. Eur. J. Environ. Civ. Eng. 20, s102-s122 (2016)

24. Baykasoğlu, A., Dereli, T.U., Taniş, S.: Prediction of cement strength using soft computing techniques. Cem. Concr. Res. 34, 2083-2090 (2004)

25. Akkurt, S., Tayfur, G., Can, S.: Fuzzy logic model for the prediction of cement compressive strength. Cem. Concr. Res. 34, 1429-1433 (2004)

26. Özcan, F., Atiş, C.D., Karahan, O., Uncuoğlu, E., Tanyildizi, H.: Comparison of artificial neural network and fuzzy logic models for prediction of long-term compressive strength of silica fume concrete. Adv. Eng. Softw. 40, 856-863 (2009)

27. Saridemir, M.: Predicting the compressive strength of mortars containing metakaolin by artificial neural networks and fuzzy logic. Adv. Eng. Softw. 40(9), 920-927 (2009)

28. Eskandari-Naddaf, H., Kazemi, R.: ANN prediction of cement mortar compressive strength, influence of cement strength class. Constr. Build. Mater. 138, 1-11 (2017)

29. Oh, T.-K., Kim, J., Lee, C., Park, S.: Nondestructive concrete strength estimation based on electro-mechanical impedance with artificial neural network. J. Adv. Concr. Technol. 15, 94-102 (2017)

30. Khademi, F., Akbari, M., Jamal, S.M., Nikoo, M.: Multiple linear regression, artificial neural network, and fuzzy logic prediction of 28 days compressive strength of concrete. Front. Struct. Civ. Eng. 11, 90-99 (2017)

31. Türkmen, İ., Bingöl, A.F., Tortum, A., Demirboğa, R., Gül, R.: Properties of pumice aggregate concretes at elevated temperatures and comparison with ANN models. Fire Mater. 41, 142-153 (2017) 
32. Nikoo, M., Zarfam, P., Sayahpour, H.: Determination of compressive strength of concrete using self organization feature map (SOFM). Eng. Comput. 31, 113-121 (2015)

33. Adeli, H.: Neural networks in civil engineering: 1989-2000. Comput.-Aided Civ. Infrastruct. Eng. 16, 126-142 (2001)

34. Safiuddin, M., Raman, S.N., Salam, M.A., Jumaat, M.Z.: Modeling of compressive strength for self-consolidating high-strength concrete incorporating palm oil fuel ash. Materials 9, 396 (2016)

35. Mansouri, I., Kisi, O.: Prediction of debonding strength for masonry elements retrofitted with FRP composites using neuro fuzzy and neural network approaches. Compos. Part B Eng. 70, 247-255 (2015)

36. Mansouri, I., Gholampour, A., Kisi, O., Ozbakkaloglu, T.: Evaluation of peak and residual conditions of actively confined concrete using neuro-fuzzy and neural computing techniques. Neural Comput. Appl. 29, 1-16 (2016). https://doi.org/10.1007/s00521-016-2492-4

37. Reddy, T.C.S.: Predicting the strength properties of slurry infiltrated fibrous concrete using artificial neural network. Front. Struct. Civ. Eng. 12, 1-14 (2017). https://doi.org/10.1007/ s11709-017-0445-3

38. Salehi, H., Burgueño, R.: Emerging artificial intelligence methods in structural engineering. Eng. Struct. 171, 170-189 (2018)

39. Bröcker, O.: Die auswertung von tragfähigkeitsversuchen an gemauerten wänden. Betonstein-Ztg. 10, 19-21 (1963)

40. Mann, W.: Statistical evaluation of tests on masonry by potential functions. In: Proceedings of the Sixth International Brick Masonry Conference, Rome, Italy, May 1982, pp. 86-98 (1982)

41. Hendry, A.W., Malek, M.H.: Characteristic compressive strength of brickwork walls from collected test results. Mason. Int. 7, 15-24 (1986)

42. Dayaratnam, P.: Brick and Reinforced Brick Structures. Oxford \& IBH, New Delhi (1987)

43. Apolo, G.L., Matinez-Luengas, A.L.: Curso Técnicas de Intervención en El Patrimonio Arquitectonico. Consultores Tecnicos de Contstruccion (1995)

44. Bennett, R., Boyd, K., Flanagan, R.: Compressive properties of structural clay tile prisms. J. Struct. Eng. 123(7), 920-926 (1997)

45. AS Committee 3700-2001. Masonry structures. Australian Standard Association, Sydney, 197 p. (2001)

46. Dymiotis, C., Gutlederer, B.M.: Allowing for uncertainties in the modelling of masonry compressive strength. Constr. Build. Mater. 16(2002), 443-452 (2002)

47. EN 1996-1-1: Eurocode 6: design of masonry structures-Part 1-1: general rules for reinforced and unreinforced masonry structures. European Committee for Standardization, Brussels (2005)

48. Gumaste, K.S., Rao, K.S.N., Reddy, B.V.V., Jagadish, K.S.: Strength and elasticity of brick masonry prisms and wallettes under compression. Mater. Struct. 40(2), 241-253 (2007)

49. Christy, C.F., Tensing, D., Shanthi, R.: Experimental study on axial compressive strength and elastic modulus of the clay and fly ash brick masonry. J. Civ. Eng. Constr. Technol. 4(4), 134-141 (2013)

50. Garzón-Roca, J., Marco, C.O., Adam, J.M.: Compressive strength of masonry made of clay bricks and cement mortar: estimation based on neural networks and fuzzy logic. Eng. Struct. 48(2013), 21-27 (2013)

51. Sarhat, S.R., Sherwood, E.G.: The prediction of compressive strength of ungrouted hollow concrete block masonry. Constr. Build. Mater. 58, 111-121 (2014)

52. Lumantarna, R., Biggs, D.T., Ingham, J.M.: Uniaxial compressive strength and stiffness of field-extracted and laboratory-constructed masonry prisms. J. Mater. Civ. Eng. 26(4), 567575 (2014) 
53. Kumavat, H.R.: An experimental investigation of mechanical properties in clay brick masonry by partial replacement of fine aggregate with clay brick waste. J. Inst. Eng. India Ser. A 97(3), 199-204 (2016)

54. British Standards Institution (BSI): BS EN 1996 (Eurocode 6): Design of Masonry Structures, British Standards Institution, p. 128 (2005)

55. Hornik, K., Stinchcombe, M., White, H.: Multilayer feedforward networks are universal approximators. Neural Netw. 2, 359-366 (1989)

56. Plevris, V., Asteris, P.G.: Modeling of masonry compressive failure using neural networks. In: Proceedings of the OPT-i 2014-1st International Conference on Engineering and Applied Sciences Optimization, Kos, Greece, 4-6 June, pp. 2843-2861 (2014)

57. Plevris, V., Asteris, P.G.: Modeling of masonry failure surface under biaxial compressive stress using neural networks. Constr. Build. Mater. 55, 447-461 (2014)

58. Plevris, V., Asteris, P.: Anisotropic failure criterion for brittle materials using artificial neural networks. In: Proceedings of the COMPDYN 2015-5th ECCOMAS Thematic Conference on Computational Methods in Structural Dynamics and Earthquake Engineering, Crete Island, Greece, 25-27 May 2015, pp. 2259-2272 (2015)

59. Giovanis, D.G., Papadopoulos, V.: Spectral representation-based neural network assisted stochastic structural mechanics. Eng. Struct. 84, 382-394 (2015)

60. Asteris, P.G., Plevris, V.: Neural network approximation of the masonry failure under biaxial compressive stress. In: Proceedings of the 3rd South-East European Conference on Computational Mechanics (SEECCM III), an ECCOMAS and IACM Special Interest Conference, Kos Island, Greece, 12-14 June 2013, pp. 584-598 (2013)

61. Asteris, P.G., Plevris, V.: Anisotropic masonry failure criterion using artificial neural networks. Neural Comput. Appl. 28, 1-23 (2016). https://doi.org/10.1007/s00521-016-2181-3

62. Asteris, P.G., Kolovos, K.G.: Self-compacting concrete strength prediction using surrogate models. Neural Comput. Appl. 1-16 (2017). https://doi.org/10.1007/s00521-017-3007-7

63. Page, A.W.: The biaxial compressive strength of brick masonry. Proc. Instn. Civ. Engrs. 71 (2), 893-906 (1981)

64. Ravula, M.B., Subramaniam, K.V.L.: Experimental investigation of compressive failure in masonry brick assemblages made with soft brick. Mater. Struct. 50(19), 1-11 (2017)

65. Singh, S.B., Munjal, P.: Bond strength and compressive stress-strain characteristics of brick masonry. J. Build. Eng. 9, 10-16 (2017)

66. Zhou, Q., Wang, F., Zhu, F.: Estimation of compressive strength of hollow concrete masonry prisms using artificial neural networks and adaptive neuro-fuzzy inference systems. Constr. Build. Mater. 125, 199-204 (2016)

67. Balasubramanian, S.R., et al.: Experimental determination of statistical parameters associated with uniaxial compression behaviour of brick masonry. Curr. Sci. 109(11), 2094-2102 (2015)

68. Vindhyashree, Rahamath, A., Kumar, W.P., Kumar, M.T.: Numerical simulation of masonry prism test using ANSYS and ABAQUS. Int. J. Eng. Res. Technol. 4(7), 1019-1027 (2015)

69. Nagarajan, S., Viswanathan, S., Ravi, V.: Experimental approach to investigate the behaviour of brick masonry for different mortar ratios. In: Proceedings of the International Conference on Advances in Engineering and Technology, Singapore, March 2014, pp. 586592 (2014)

70. Thamboo, J.A.: Development of thin layer mortared concrete masonry. Ph.D. dissertation, Queensland University of Technology, Brisbane (2014)

71. Vimala, S., Kumarasamy, K.: Studies on the strength of stabilized mud block masonry using different mortar proportions. Int. J. Emerg. Technol. Adv. Eng. 4(4), 720-724 (2014)

72. Reddy, B.V., Vyas, C.V.U.: Influence of shear bond strength on compressive strength and stress-strain characteristics of masonry. Mater. Struct. 41(10), 1697-1712 (2008) 
73. Mohamad, G., Lourenço, P.B., Roman, H.R.: Mechanics of hollow concrete block masonry prisms under compression: review and prospects. Cement Concrete Comp. 29(3), 181-192 (2007)

74. Brencich, A., Gambarotta, L.: Mechanical response of solid clay brickwork under eccentric loading. Part I: unreinforced masonry. Mater. Struct. 38, 257-266 (2005)

75. Bakhteri, J., Sambasivam, S.: Mechanical behaviour of structural brick masonry: an experimental evaluation. In: Proceedings of the 5th Asia - Pacific Structural Engineering and Construction Conference, Johor Bahru, Malaysia, August 2003, pp. 305-317 (2003)

76. Ip, F.: Compressive strength and modulus of elasticity of masonry prisms. Master of Engineering thesis, Carleton University, Ottawa (1999)

77. Hossain, M.M., Ali, S.S., Rahman, M.A.: Properties of masonry constituents. J. Civil Eng. Inst. Eng. Bangladesh 25(2), 135-155 (1997)

78. Vermeltfoort, A.T.: Compression properties of masonry and its components. In: Proceedings of the 10th International Brick and Block Masonry Conference, Calgary, Canada, vol. 3, pp. 1433-1442 (1994)

79. McNary, W., Abrams, D.: Mechanics of masonry in compression. J. Struct. Eng. 111(4), $857-870(1985)$

80. Francis, A.J., Horman, A.A., Jerrems, L.E.: The effect of joint thickness and other factors on the compressive strength of brickwork. In: SIBMAC Proceedings of 2nd International Brick and Block Masonry Conference, Stoke on Trent, pp. 31-37 (1970)

81. IS: 383: Indian Standard Specification for Coarse and Fine Aggregates from Natural Sources for Concrete. Bureau of Indian Standards, New Delhi, India (1970)

82. IS: 2250: Indian Standard Code of Practice for Preparation and Use of Masonry Mortars. Bureau of Indian Standards, New Delhi, India (1981)

83. N.N. Common unified rules for masonry structures, Eurocode No. 6, CEN

84. Lourakis, M.I.A.: A brief description of the Levenberg-Marquardt algorithm Implemened by levmar, Hellas (FORTH). Institute of Computer Science Foundation for Research and Technology (2005). http://www.ics.forth.gr/ lourakis/levmar/levmar

85. Asteris, P.G., Nozhati, S., Nikoo, M., Cavaleri, L., Nikoo, M.: Krill herd algorithm-based neural network in structural seismic reliability evaluation. Mech. Adv. Mater. Struct. (Article in press). https://doi.org/10.1080/15376494.2018.1430874

86. Asteris, P.G., Roussis, P.C., Douvika, M.G.: Feed-forward neural network prediction of the mechanical properties of sandcrete materials. Sensors (Switzerland) 17(6), 1344 (2017)

87. Cavaleri, L., et al.: Modeling of surface roughness in electro-discharge machining using artificial neural networks. Adv. Mater. Res. (South Korea) 6(2), 169-184 (2017)

88. Asteris, P.G., et al.: Prediction of the fundamental period of infilled RC frame structures using artificial neural networks. Comput. Intell. Neurosci. 2016, 12 (2016). 5104907

89. Nikoo, M., Hadzima-Nyarko, M., Karlo Nyarko, E., Nikoo, M.: Determining the natural frequency of cantilever beams using ANN and heuristic search. Appl. Artif. Intell. 32(3), 309-334 (2018)

90. Nikoo, M., Ramezani, F., Hadzima-Nyarko, M., Nyarko, E.K., Nikoo, M.: Flood-routing modeling with neural network optimized by social-based algorithm. Natural Hazards 82(1), 1-24 (2016)

91. Nikoo, M., Sadowski, L., Khademi, F., Nikoo, M.: Determination of damage in reinforced concrete frames with shear walls using self-organizing feature map. Appl. Comput. Intell. Soft Comput. 2017, 10 (2017). 3508189

92. Anscombe, F.J.: Graphs in statistical analysis. Am. Stat. 27(1), 17-21 (1973) 